\title{
On $\alpha$ Generalized Closed Sets In Ideal Topological Spaces
}

\author{
S.Maragathavalli ${ }^{1}$ and D.Vinodhini ${ }^{2}$ \\ ${ }^{I}$ Department of Mathematics, Karpagam University Coimbatore, TamilNadu,India \\ ${ }^{2}$ Department of Mathematics, SVS College of Engineering ,Coimbatore, TamilNadu, India
}

\begin{abstract}
In this research paper, we are introducing the concept of $\alpha$-generalized closed sets in Ideal topological space and discussed the characterizations and the properties of $\alpha$-generalized closed sets in Ideal topological space.
\end{abstract}

Keywords: Ig closed sets, I $\widehat{\boldsymbol{g}}$-closed set, $\alpha$ Ig-closed sets, Semi- I closed set, Pre-I closed set, $\alpha$ - I closed set,b-I closed set.

\section{Introduction}

The notion of $\alpha$-open sets was introduced and investigated by Njastad[1]. By using $\alpha$-open sets, Mashhour et al.[2] defined and studied the concept of $\alpha$-closed sets, $\alpha$-closure of a set, $\alpha$-continuity and $\alpha$ closedness in topology. Ideals in topological spaces have been considered since 1930. This topic has won its importance by the paper of Vaidyanathaswamy[3]. It was the works of Newcomb[4], Rancin[5], Samuels and Hamlet and Jankovic([6, 7, 8, 9, 10]) which motivated the research in applying topological ideals to generalize the most basic properties in General Topology.

\section{Preliminaries}

An ideal I on a topological space $(\mathrm{X}, \tau)$ is a nonempty collection of subsets of $\mathrm{X}$, which satisfies the following two conditions:

(i) If $\mathrm{A} \in \mathrm{I}$ and $\mathrm{B} \subseteq \mathrm{A}$ implies $\mathrm{B} \in \mathrm{I}$

(ii) If $A \in \boldsymbol{I}$ and $\mathrm{B} \boldsymbol{\epsilon} \mathrm{I}$, then $\mathrm{A} \cup \mathrm{B} \boldsymbol{\epsilon} \mathrm{I}[11]$.

An ideal topological space is a topological space $(X, \tau)$ with an ideal I on $X$ and it is denoted by $(X, \tau, I)$. Given a topological space $(X, \tau)$ with an ideal I on $X$ and if $\boldsymbol{\rho}(\boldsymbol{X})$ is the set of all subsets of $\mathrm{X}$, a set operator $\left(^{*}\right)$ : $\boldsymbol{\rho}(\boldsymbol{X}) \rightarrow \boldsymbol{\rho}(\boldsymbol{X})$, called a local function[11] of A with respect to $\tau$ and I, is defined as follows: for $\mathrm{A} \subseteq \mathrm{X}$, $A^{*}(I, \tau)=\{x \in X / U \cap A \notin I$ for every $U \in \tau(x)\}$ where $\tau(x)=\{U \in \tau / x \in U\}$. We simply write $A^{*}$ instead of $A^{*}(I, \tau)$. For every Ideal topological space $(\mathrm{X}, \tau, \mathrm{I})$, there exists a topology $\tau^{*}(\mathrm{I})$, finer than $\tau$, generated by $\boldsymbol{\beta}(\boldsymbol{I}, \boldsymbol{\tau})=$ $\{\mathrm{U}-\mathrm{i} / \mathrm{U} \boldsymbol{\epsilon} \dot{\varepsilon} \boldsymbol{i} \boldsymbol{\epsilon} \mathrm{I}\}$. But in general $(\boldsymbol{I}, \boldsymbol{\tau})$ is not always a topology. Additionally $\mathrm{cl}^{*}(\mathrm{~A})=\mathrm{A} \cup \mathrm{A}^{*}$ defines a kuratowski closure operator for $\tau^{*}(\mathrm{I})$. If $\mathrm{A} \subseteq \mathrm{X}, \operatorname{cl}(\mathrm{A})$ and $\operatorname{int}(\mathrm{A})$ will, respectively, denote the closure and interior of $\mathrm{A}$ in $(\mathrm{X}, \tau)$ and $\operatorname{int}^{*}(\mathrm{~A})$ denote the interior of $\mathrm{A}$ in $\left(\mathrm{X}, \tau^{*}\right)$. A subset $\mathrm{A}$ of an ideal space $(\mathrm{X}, \tau, \mathrm{I})$ is $*$-closed(resp. *-dense in itself) if $A^{*} \subseteq A\left(\right.$ resp. $\left.A \subseteq A^{*}\right)$.

Definition 2.1[13]

A subset $\mathrm{A}$ of a topological space $(\mathrm{X}, \tau)$ is called a generalized closed set (briefly g-closed) if $\mathrm{cl}(\mathrm{A}) \subseteq \mathrm{A}$ whenever $\mathrm{A} \subseteq \mathrm{U}$ and $\mathrm{U}$ is open in $(\mathrm{X}, \tau)$.

\section{Definition 2.2[15]}

A subset $\mathrm{A}$ of a topological space $(\mathrm{X}, \tau)$ is called a $\alpha$-generalized closed set (briefly $\alpha$ g-closed set) if $\alpha \mathrm{cl}(\mathrm{A}) \subseteq \mathrm{U}$ whenever $\mathrm{A} \subseteq \mathrm{U}$ and $\mathrm{U}$ is open in $(\mathrm{X}, \tau)$.

\section{Definition 2.3[15]}

A subset $\mathrm{A}$ of a topological space $(\mathrm{X}, \tau)$ is called $\hat{\mathbf{g}}$-closed if $\mathrm{cl}(\mathrm{A}) \subseteq \mathrm{U}$ whenever $\mathrm{A} \subseteq \mathrm{U}$ and $\mathrm{U}$ is semi-open.

\section{Definition 2.4[15]}

A subset $A$ of a topological space $(X, \tau)$ is said to be

(i) $\quad$ Pre closed set if $\mathrm{cl}($ int $(\mathrm{A})) \subseteq \mathrm{A}$.

(ii) Semi closed set if int $(\mathrm{cl}(\mathrm{A})) \subseteq \mathrm{A}$.

(iii) $\quad \alpha$-closed set if $\operatorname{cl}(\operatorname{int}(\mathrm{cl}(\mathrm{A}))) \subseteq \mathrm{A}$.

(iv) $\quad$ b- closed set if $\operatorname{cl}(\operatorname{int}(\mathrm{A})) \cup \operatorname{int}(\mathrm{cl}(\mathrm{A})) \subseteq \mathrm{A}$. 


\section{Definition 2.5[12]}

Let $(X, \tau)$ be a topological space and $I$ be an ideal on $X$. A subset $A$ of $X$ is said to be Ideal generalized closed set (briefly Ig- closed set) if $\mathrm{A}^{*} \subseteq \mathrm{U}$ whenever $\mathrm{A} \subseteq \mathrm{U}$ and $\mathrm{U}$ is open.

\section{Definition 2.6[14]}

A subset $\mathrm{A}$ of an ideal topological space $(\mathrm{X}, \tau, \mathrm{I})$ is said to be

(i) $\quad$ pre-I-closed set if cl $^{*}(\operatorname{int}(\mathrm{A})) \subseteq \mathrm{A}$.

(ii) semi-I-closed set if $\operatorname{int}\left(\mathrm{cl}^{*}(\mathrm{~A})\right) \subseteq \mathrm{A}$.

(iii) $\quad \alpha$-I-closed set if $\operatorname{cl}^{*}\left(\operatorname{int}\left(\mathrm{cl}^{*}(\mathrm{~A})\right)\right) \subseteq \mathrm{A}$.

(iv) $\quad$ b-I-closed set if $\mathrm{cl}^{*}(\operatorname{int}(\mathrm{A})) \cup \operatorname{int}\left(\mathrm{cl}^{*}(\mathrm{~A})\right) \subseteq \mathrm{A}$.

\section{Definition 2.7 [11]}

Let $(X, \tau)$ be a topological space and I be an ideal on X. A subset $A$ of $X$ is said to be I $\hat{g}$-closed set if $A^{*} \subseteq U$ whenever $\mathrm{A} \subseteq \mathrm{U}$ and $\mathrm{U}$ is semi-open.

\section{Lemma 2.8:[12]}

Let $(\mathrm{X}, \tau, \mathrm{I})$ be an ideal topological space and $\mathrm{A}, \mathrm{B}$ subsets of $\mathrm{X}$. Then the following properties hold:

(i) $\quad \mathrm{A} \subseteq \mathrm{B} \Rightarrow \mathrm{A}^{*} \subseteq \mathrm{B}^{*}$,

(ii) $\mathrm{A}^{*}=\operatorname{cl}\left(\mathrm{A}^{*}\right) \subseteq \operatorname{cl}(\mathrm{A})$,

(iii) $\quad\left(\mathrm{A}^{*}\right)^{*} \subseteq \mathrm{A}^{*}$,

(iv) $\quad(\mathrm{A} \cup \mathrm{B})^{*}=\mathrm{A}^{*} \cup \mathrm{B}^{*}$,

(v) $\quad(\mathrm{A} \cap \mathrm{B})^{*} \subseteq \mathrm{A}^{*} \cap \mathrm{B}^{*}$.

\section{III. $\quad \alpha$-Ideal Generalized Closed sets}

\section{Definition 3.1}

Let $(\mathrm{X}, \tau)$ be a topological space and $\mathrm{I}$ be an ideal on $\mathrm{X}$. A subset $\mathrm{A}$ of $\mathrm{X}$ is said to be $\alpha$-Ideal generalized closed set (briefly $\alpha \mathrm{Ig}$ - closed set) if $\mathrm{A}^{*} \subseteq \mathrm{U}$ whenever $\mathrm{A} \subseteq \mathrm{U}$ and $\mathrm{U}$ is $\alpha$-open.

\section{Example 3.2}

Let $\mathrm{X}=\{\mathrm{a}, \mathrm{b}, \mathrm{c}\}$ with topology $\tau=\{\Phi, \mathrm{X},\{\mathrm{a}\},\{\mathrm{b}\},\{\mathrm{a}, \mathrm{b}\}\}$ and $\mathrm{I}=\{\Phi,\{\mathrm{b}\}\}$. The set $\mathrm{A}=\{\mathrm{a}, \mathrm{c}\}$, where $\mathrm{A}^{*}=\{\mathrm{a}, \mathrm{c}\}$ is an $\alpha I g-$ closed set.

\section{Definition 3.3}

Let $(X, \tau)$ be a topological space and $\mathrm{I}$ be an ideal on $\mathrm{X}$. A subset $\mathrm{A}$ of $\mathrm{X}$ is said to be $\alpha$-Ideal generalized open set (briefly $\alpha$ Ig- open set) if $\mathrm{X}-\mathrm{A}$ is $\alpha \mathrm{Ig}$ - closed set.

\section{Theorem 3.4}

If $(X, \tau, I)$ is any ideal space and $A \subseteq X$, then the following are equivalent.
(a) A is $\alpha$ Ig-closed.
(b) $\mathrm{cl}^{*}(\mathrm{~A}) \subseteq \mathrm{U}$ whenever $\mathrm{A} \subseteq \mathrm{U}$ and $\mathrm{U}$ is $\alpha$-open in $\mathrm{X}$.
(c) For all $\mathrm{x} \epsilon \mathrm{cl}^{*}(\mathrm{~A}), \alpha \mathrm{cl}(\{\mathrm{x}\}) \cap \mathrm{A} \neq \Phi$.
(d) $\mathrm{cl}^{*}(\mathrm{~A})-\mathrm{A}$ contains no nonempty $\alpha$-closed set.
(e) $A^{*}-A$ contains no nonempty $\alpha$-closed set.

\section{Proof}

(a) $\Rightarrow$ (b): If $A$ is $\alpha$ Ig-closed, then $A^{*} \subseteq U$ whenever $A \subseteq U$ and $U$ is $\alpha$-open in $X$ and so cl $^{*}(A)=A \cup A^{*} \subseteq U$ whenever $\mathrm{A} \subseteq \mathrm{U}$ and $\mathrm{U}$ is $\alpha$-open in $\mathrm{X}$. This proves (b).

(b) $\Rightarrow(\mathbf{c}):$ Suppose $\mathrm{x} \in \operatorname{cl}^{*}(\mathrm{~A})$. If $\alpha \operatorname{cl}(\{\mathrm{x}\}) \cap \mathrm{A}=\Phi$, then $\mathrm{A} \subseteq \mathrm{X}-\alpha \mathrm{cl}(\{\mathrm{x}\})$. By $(\mathrm{b}), \mathrm{cl}^{*}(\mathrm{~A}) \subseteq \mathrm{X}-\alpha \mathrm{cl}(\{\mathrm{x}\})$, which is a contradiction to $\mathrm{x} \in \mathrm{cl}^{*}(\mathrm{~A})$. This proves (c).

(c) $\Rightarrow(\mathbf{d})$ : Suppose $\mathrm{F} \subseteq \mathrm{cl}^{*}(\mathrm{~A})-\mathrm{A}, \mathrm{F}$ is $\alpha$-closed and $\mathrm{x} \in \mathrm{F}$. Since $\mathrm{F} \subseteq \mathrm{X}-\mathrm{A}$ and $\mathrm{F}$ is $\alpha$-closed, then $\mathrm{A} \subseteq \mathrm{X}-\mathrm{F}$ and hence $\alpha \mathrm{cl}(\{\mathrm{x}\}) \cap A=\Phi$. Since $\mathrm{x} \in \mathrm{cl}^{*}(\mathrm{~A})$ by $(\mathrm{c}), \alpha \mathrm{cl}(\{\mathrm{x}\}) \cap \mathrm{A} \neq \Phi$. Therefore, $\mathrm{cl}^{*}(\mathrm{~A})-\mathrm{A}$ contains no nonempty $\alpha$-closed set.

(d) $\Rightarrow\left(\right.$ e) : Since $c l^{*}(A)-A=\left(A \cup A^{*}\right)-A=\left(A \cup A^{*}\right) \cap A^{c}=\left(A \cap A^{c}\right) \cup\left(A^{*} \cap A^{c}\right)=A^{*} \cap A^{c}=A^{*}-A$. Therefore, $\mathrm{A}^{*}-\mathrm{A}$ contains no nonempty $\alpha$-closed set. 
(e) $\Rightarrow$ (a): Let $\mathrm{A} \subseteq \mathrm{U}$ where $\mathrm{U}$ is $\alpha$-open set. Therefore $\mathrm{X}-\mathrm{U} \subseteq \mathrm{X}-\mathrm{A}$ and so $\mathrm{A}^{*} \cap(\mathrm{X}-\mathrm{U}) \subseteq \mathrm{A}^{*} \cap(\mathrm{X}-\mathrm{A})=\mathrm{A}^{*}-\mathrm{A}$. Therefore $A^{*} \cap(X-U) \subseteq A^{*}-A$. Since $A^{*}$ is always closed set, $A^{*} \cap(X-U)$ is a $\alpha$-closed set contained in $A^{*}-A$. Therefore, $\mathrm{A}^{*} \cap(\mathrm{X}-\mathrm{U})=\Phi$ and hence $\mathrm{A}^{*} \subseteq \mathrm{U}$. Therefore, $\mathrm{A}$ is $\alpha$ Ig-closed.

\section{Theorem 3.5}

Every *-closed set is $\alpha$ Ig-closed set but not conversely.

Proof:

Let $\mathrm{A}$ be a $*$-closed, then $\mathrm{A}^{*} \subseteq \mathrm{A}$. Let $\mathrm{A} \subseteq \mathrm{U}$, and $\mathrm{U}$ is $\alpha$-open. This implies $\mathrm{A}^{*} \subseteq \mathrm{U}$. Hence $\mathrm{A}$ is $\alpha \mathrm{Ig}$-closed.

\section{Example 3.6}

Let $X=\{a, b, c\}$ with topology $\tau=\{\Phi, X,\{a\},\{b, c\}\}$ and $I=\{\Phi,\{c\}\}$. It is clear that $A=\{b\}$ is $\alpha$ Ig-closed set since $A^{*}=\{b, c\} \subseteq U$ where $U$ is $\alpha$-open. But $A$ is not a $*$-closed set.

\section{Remark 3.7}

$\alpha I g$ - closed set and $\alpha I$-closed set are independent to each other, as seen from the following examples.

\section{Example 3.8}

Let $\mathrm{X}=\{\mathrm{a}, \mathrm{b}, \mathrm{c}\}$ with topology $\tau=\{\Phi,\{\mathrm{a}\},\{\mathrm{b}, \mathrm{c}\}, \mathrm{X}\}$ and $\mathrm{I}=\{\Phi,\{\mathrm{c}\}\}$. Clearly, the set $\mathrm{A}=\{\mathrm{b}\}$ which is an $\alpha \mathrm{Ig}$-closed set is not an $\alpha \mathrm{I}$ - closed set since $\operatorname{cl}^{*}\left(\operatorname{int}\left(\mathrm{cl}^{*}(\mathrm{~A})\right)\right)=\{\mathrm{b}, \mathrm{c}\} \not \subset \mathrm{A}$.

\section{Example 3.9}

Let $\mathrm{X}=\{\mathrm{a}, \mathrm{b}, \mathrm{c}\}$ with topology $\tau=\{\Phi,\{\mathrm{a}\},\{\mathrm{a}, \mathrm{c}\}, \mathrm{X}\}$ and $\mathrm{I}=\{\Phi,\{\mathrm{b}\}\}$. It is clear that $\mathrm{A}=\{\mathrm{c}\}$ is an $\alpha \mathrm{I}-$ closed set. But $A$ is not an $\alpha$ Ig-closed set since $A^{*}=\{b, c\} \not \subset U$.

\section{Remark 3.10}

aIg- closed set and semi I-closed set are independent to each other, as seen from the following examples.

\section{Example 3.11}

Let $\mathrm{X}=\{\mathrm{a}, \mathrm{b}, \mathrm{c}\}$ with topology $\tau=\{\Phi,\{\mathrm{a}\},\{\mathrm{b}, \mathrm{c}\}, \mathrm{X}\}$ and $\mathrm{I}=\{\Phi,\{\mathrm{c}\}\}$. Clearly, the set $\mathrm{A}=\{\mathrm{b}\}$ is an $\alpha$ Ig-closed set but not semi I- closed set since int(cl* $(A))=\{b, c\} \not \subset A$.

\section{Example 3.12}

Let $X=\{a, b, c\}$ with topology $\tau=\{\Phi,\{a\},\{b\},\{a, b\}, X\}$ and $I=\{\Phi,\{a\}\}$. It is clear that $A=\{b\}$ which is semi Iclosed set. But $A$ is not an $\alpha I$-closed set since $A^{*}=\{b, c\} \not \subset U$.

\section{Remark 3.13}

Every pre I-closed set need not be an $\alpha$ Ig- closed set.

\section{Example 3.14}

Let $\mathrm{X}=\{\mathrm{a}, \mathrm{b}, \mathrm{c}\}$ with topology $\tau=\{\Phi,\{\mathrm{a}\},\{\mathrm{a}, \mathrm{c}\}, \mathrm{X}\}$ and $\mathrm{I}=\{\Phi,\{\mathrm{b}\}\}$. Clearly, the set $\mathrm{A}=\{\mathrm{c}\}$ is pre I- closed set but not an $\alpha$ Ig- closed set since $A^{*}=\{b, c\} \not \subset U$.

\section{Remark 3.15}

$\alpha I g$ - closed set and b I-closed set are independent to each other, as seen from the following examples.

\section{Example 3.16}

Let $X=\{a, b, c\}$ with topology $\tau=\{\Phi,\{a\},\{b, c\}, X\}$ and $I=\{\Phi,\{c\}\}$. Clearly, the set $A=\{a, b\}$ is an alg-closed set, but not a b I-closed set, since $\mathrm{cl}^{*}(\operatorname{int}(\mathrm{A})) \cup \operatorname{int}\left(\mathrm{cl}^{*}(\mathrm{~A})\right)=\mathrm{X} \not \subset \mathrm{A}$.

\section{Example 3.17}

Let $\mathrm{X}=\{\mathrm{a}, \mathrm{b}, \mathrm{c}\}$ with topology $\tau=\{\Phi,\{\mathrm{a}\},\{\mathrm{a}, \mathrm{c}\}, \mathrm{X}\}$ and $\mathrm{I}=\{\Phi,\{\mathrm{b}\}\}$. It is clear that $\mathrm{A}=\{\mathrm{c}\}$ is bI-closed set. But $A$ is not an $\alpha$ Ig-closed set since $A^{*}=\{b, c\} \not \subset U$.

\section{Theorem 3.18}

Every $\alpha$ Ig-closed set is an Ig-closed set but not conversely. 
Proof

Let $A \subseteq U$ and $U$ is open. Clearly every open set is $\alpha$-open. Since $A$ is $\alpha$ Ig-closed set, $A^{*} \subseteq U$, which implies that $\mathrm{A}$ is an Ig-closed set.

\section{Example 3.19}

Let $\mathrm{X}=\{\mathrm{a}, \mathrm{b}, \mathrm{c}\}$ with topology $\tau=\{\Phi,\{\mathrm{a}\},\{\mathrm{a}, \mathrm{c}\}, \mathrm{X}\}$ and $\mathrm{I}=\{\Phi,\{\mathrm{b}\}\}$. Clearly, the set $\mathrm{A}=\{\mathrm{a}, \mathrm{b}\}$ is Ig- closed set but not an $\alpha \mathrm{Ig}$ - closed set since $\mathrm{A}^{*}=\mathrm{X} \not \subset \mathrm{U}$.

\section{Theorem 3.20}

Every I $\mathbf{g}$-closed set is an $\alpha$ Ig-closed set.

Proof

Let $A \subseteq U$ and $U$ is $\alpha$-open. Clearly, every $\alpha$-open set is semi-open. Since A is I $\hat{\mathbf{g}}$-closed set, $A^{*} \subseteq U$, which implies that $\mathrm{A}$ is an $\alpha \mathrm{Ig}$ - closed set.

\section{Theorem 3.21}

Let $(\mathrm{X}, \tau, \mathrm{I})$ be an ideal space. For every $\mathrm{A} \in \mathrm{I}$, A is $\alpha \mathrm{Ig}$-closed set.

Proof

Let $\mathrm{A} \subseteq \mathrm{U}$ where $\mathrm{U}$ is $\alpha$-open set. Since $\mathrm{A}^{*}=\Phi$ for every $\mathrm{A} \in \mathrm{I}$, then $\mathrm{A}^{*} \subseteq \mathrm{A}$. This implies $\mathrm{A}^{*} \subseteq \mathrm{U}$. Hence for every $\mathrm{A} \in \mathrm{I}, \mathrm{A}$ is an $\alpha \mathrm{Ig}$-closed set.

\section{Theorem 3.22}

If $\mathrm{A}$ and $\mathrm{B}$ are $\alpha \mathrm{Ig}$-closed sets in $(\mathrm{X}, \tau, \mathrm{I})$, then $\mathrm{A} \cup \mathrm{B}$ is also an $\alpha \mathrm{Ig}$-closed set.

\section{Proof}

Let $\mathrm{A} \cup \mathrm{B} \subseteq \mathrm{U}$ where $\mathrm{U}$ is $\alpha$-open in $\mathrm{X}$. Then $\mathrm{A} \subseteq \mathrm{U}$ and $\mathrm{B} \subseteq \mathrm{U}$. Since $\mathrm{A}$ and $\mathrm{B}$ are $\alpha$ Ig-closed set, then $\mathrm{A}^{*} \subseteq \mathrm{U}$ and $\mathrm{B}^{*} \subseteq \mathrm{U}$ and so $\mathrm{A}^{*} \cup \mathrm{B}^{*} \subseteq \mathrm{U}$. By Lemma 2.8(iv), $(\mathrm{A} \cup \mathrm{B})^{*}=\mathrm{A}^{*} \cup \mathrm{B}^{*} \subseteq \mathrm{U}$. Hence $\mathrm{A} \cup \mathrm{B}$ is an $\alpha \operatorname{Ig}$-closed set.

\section{Remark 3.23}

The intersection of $\alpha$ Ig-closed sets need not be an $\alpha$ Ig-closed set as shown from the following example.

\section{Example 3.24}

Let $\mathrm{X}=\{\mathrm{a}, \mathrm{b}, \mathrm{c}, \mathrm{d}\}$ with topology $\tau=\{\Phi,\{\mathrm{a}\},\{\mathrm{d}\},\{\mathrm{a}, \mathrm{d}\}, \mathrm{X}\}$ and $\mathrm{I}=\{\Phi,\{\mathrm{d}\}\}$. If $\mathrm{A}=\{\mathrm{b}, \mathrm{c}\}, \mathrm{B}=\{\mathrm{b}, \mathrm{d}\}$, then $\mathrm{A}$ and $\mathrm{B}$ are $\alpha$ Ig-closed sets but their intersection $A \cap B=\{b\}$ is not an $\alpha$ Ig- closed set.

\section{Theorem 3.25}

If $(X, \tau, I)$ is an ideal space, then $A^{*}$ is always an $\alpha$ Ig-closed set for every subset $\mathrm{A}$ of $\mathrm{X}$.

\section{Proof}

Let $A^{*} \subseteq U$, where $U$ is $\alpha$-open. Since $\left(A^{*}\right)^{*} \subseteq A^{*}[12]$, we have $\left(A^{*}\right)^{*} \subseteq U$ whenever $A^{*} \subseteq U$ and $U$ is $\alpha$-open. Hence $\mathrm{A}^{*}$ is an $\alpha \mathrm{Ig}$-closed set.

\section{Theorem 3.26}

If $(\mathrm{X}, \tau, \mathrm{I})$ is an ideal space, then every $\alpha$ Ig-closed, which is $\alpha$-open is $*$-closed set.

\section{Proof}

Let $\mathrm{A}$ be an $\alpha \mathrm{Ig}$-closed and $\alpha$-open set. Then $\mathrm{A} \subseteq \mathrm{A}$ implies $\mathrm{A}^{*} \subseteq \mathrm{A}$ since $\mathrm{A}$ is $\alpha$-open. Therefore, $\mathrm{A}$ is *-closed set.

\section{Theorem 3.27}

Let $(\mathrm{X}, \tau, \mathrm{I})$ be an ideal topological space and $\mathrm{A}$ be an $\alpha \mathrm{Ig}$-closed set. Then the following are equivalent.
(a) $\mathrm{A}$ is a $*$-closed set.
(b) $\mathrm{cl}^{*}(\mathrm{~A})-\mathrm{A}$ is a $\alpha$-closed set.
(c) $\mathrm{A}^{*}-\mathrm{A}$ is a $\alpha$-closed set. 
Proof

(a) $\Rightarrow(\mathbf{b})$ : If $A$ is *-closed, then $A^{*} \subseteq A$ and so $\mathrm{cl}^{*}(\mathrm{~A})-\mathrm{A}=\left(\mathrm{A} \cup \mathrm{A}^{*}\right)-\mathrm{A}=\Phi$. Hence $\mathrm{cl}^{*}(\mathrm{~A})-\mathrm{A}$ is $\alpha$-closed set.

(b) $\Rightarrow\left(\right.$ c): Since $\mathrm{cl}^{*}(\mathrm{~A})-\mathrm{A}=\mathrm{A}^{*}-\mathrm{A}$ and so $\mathrm{A}^{*}-\mathrm{A}$ is $\alpha$-closed set.

(c) $\Rightarrow$ (a): If $A^{*}-A$ is a $\alpha$-closed set, then by Theorem $3.4, A^{*}-A=\Phi$ and so $A$ is *-closed.

\section{Theorem 3.28}

Let $(\mathrm{X}, \tau, \mathrm{I})$ be an ideal space and $\mathrm{A} \subseteq \mathrm{X}$. Then $\mathrm{A}$ is $\alpha \mathrm{Ig}$-closed if and only if $\mathrm{A}=\mathrm{F}-\mathrm{N}$, where $\mathrm{F}$ is *-closed and $\mathrm{N}$ contains no nonempty $\alpha$-closed set.

\section{Proof}

If $\mathrm{A}$ is $\alpha$ Ig-closed, then by Theorem 3.4(e), $\mathrm{N}=\mathrm{A}^{*}-\mathrm{A}$ contains no nonempty $\alpha$-closed set. If $\mathrm{F}=\mathrm{cl} *(\mathrm{~A})$, then $\mathrm{F}$ is *-closed such that $\mathrm{F}-\mathrm{N}=\left(\mathrm{A} \cup \mathrm{A}^{*}\right)-\left(\mathrm{A}^{*}-\mathrm{A}\right)=\left(\mathrm{A} \cup \mathrm{A}^{*}\right) \cap\left(\mathrm{A}^{*} \cap \mathrm{A}^{\mathrm{c}}\right)^{\mathrm{c}}=\left(\mathrm{A} \cup \mathrm{A}^{*}\right) \cap\left(\left(\mathrm{A}^{*}\right)^{\mathrm{c}} \cup \mathrm{A}\right)=$ $\left(\mathrm{A} \cup \mathrm{A}^{*}\right) \cap\left(\mathrm{A} \cup\left(\mathrm{A}^{*}\right)^{\mathrm{c}}\right)=\mathrm{A} \cup\left(\mathrm{A}^{*} \cap\left(\mathrm{A}^{*}\right)^{\mathrm{c}}\right)=\mathrm{A}$.

Conversely, suppose $\mathrm{A}=\mathrm{F}-\mathrm{N}$ where $\mathrm{F}$ is *-closed and $\mathrm{N}$ contains no nonempty $\alpha$-closed set. Let $\mathrm{U}$ be a $\alpha$-open set such that $\mathrm{A} \subseteq \mathrm{U}$. Then $\mathrm{F}-\mathrm{N} \subseteq \mathrm{U} \Rightarrow \mathrm{F} \cap(\mathrm{X}-\mathrm{U}) \subseteq \mathrm{N}$. Now $\mathrm{A} \subseteq \mathrm{F}$ and $\mathrm{F}^{*} \subseteq \mathrm{F}$ then $\mathrm{A}^{*} \subseteq \mathrm{F}^{*}$ and so $\mathrm{A}^{*} \cap(\mathrm{X}-\mathrm{U}) \subseteq \mathrm{F}^{*} \cap(\mathrm{X}-\mathrm{U}) \subseteq \mathrm{F} \cap(\mathrm{X}-\mathrm{U}) \subseteq \mathrm{N}$. By hypothesis, since $\mathrm{A}^{*} \cap(\mathrm{X}-\mathrm{U})$ is $\alpha$-closed, $\mathrm{A}^{*} \cap(\mathrm{X}-\mathrm{U})=\Phi$ and so $\mathrm{A}^{*} \subseteq \mathrm{U}$. Hence $\mathrm{A}$ is $\alpha \mathrm{Ig}$-closed.

\section{Lemma 3.29[11]}

Let $(\mathrm{X}, \tau, \mathrm{I})$ be an ideal space and $\mathrm{A} \subseteq \mathrm{X}$. If $\mathrm{A} \subseteq \mathrm{B} \subseteq \mathrm{A}^{*}$, then $\mathrm{A}^{*}=\mathrm{B}^{*}$ and $\mathrm{B}$ is $*$-dense in itself.

\section{Theorem 3.30}

Let $(\mathrm{X}, \tau, \mathrm{I})$ be an ideal space. If $\mathrm{A}$ and $\mathrm{B}$ are subsets of $\mathrm{X}$ such that $\mathrm{A} \subseteq \mathrm{B} \subseteq \mathrm{cl}^{*}(\mathrm{~A})$ and $\mathrm{A}$ is $\alpha \mathrm{Ig}$-closed , then $\mathrm{B}$ is $\alpha \mathrm{Ig}$-closed.

\section{Proof}

Since A is $\alpha$ Ig-closed then by Theorem 3.4(d), $\mathrm{cl}^{*}(\mathrm{~A})-\mathrm{A}$ contains no nonempty $\alpha$-closed set. Since $\mathrm{cl}^{*}(\mathrm{~B})-\mathrm{B}$ $\subseteq \mathrm{cl}^{*}(\mathrm{~A})-\mathrm{A}$ and so $\mathrm{cl}^{*}(\mathrm{~B})-\mathrm{B}$ contains no nonempty $\alpha$-closed set. Hence B is $\alpha$ Ig-closed set.

\section{Theorem 3.31}

Let $(\mathrm{X}, \tau, \mathrm{I})$ be an ideal space and $\mathrm{A} \subseteq \mathrm{X}$. Then, $\mathrm{A}$ is $\alpha$ Ig-open if and only if $\mathrm{F} \subseteq$ int $^{*}(\mathrm{~A})$ whenever $\mathrm{F}$ is $\alpha$-closed and $\mathrm{F} \subseteq \mathrm{A}$.

\section{Proof}

Suppose that $\mathrm{A}$ is $\alpha \mathrm{Ig}$-open. Let $\mathrm{F} \subseteq \mathrm{A}$ and $\mathrm{F}$ be $\alpha$-closed. Then $\mathrm{X}-\mathrm{A} \subseteq \mathrm{X}-\mathrm{F}$ and $\mathrm{X}-\mathrm{F}$ is $\alpha$-open. Since $\mathrm{X}-\mathrm{A}$ is $\alpha \mathrm{Ig}$-closed, then $(\mathrm{X}-\mathrm{A})^{*} \subseteq \mathrm{X}-\mathrm{F}$ and $\mathrm{X}-$ int $^{*}(\mathrm{~A})=\mathrm{cl}^{*}(\mathrm{X}-\mathrm{A})=(\mathrm{X}-\mathrm{A}) \cup(\mathrm{X}-\mathrm{A})^{*} \subseteq \mathrm{X}-\mathrm{F}$ and hence $\mathrm{F} \subseteq \operatorname{int}^{*}(\mathrm{~A})$.

Conversly, Let $\mathrm{X}-\mathrm{A} \subseteq \mathrm{U}$ where $\mathrm{U}$ is $\alpha$-open. Then $\mathrm{X}-\mathrm{U} \subseteq \mathrm{A}$ and $\mathrm{X}-\mathrm{U}$ is $\alpha$-closed. By hypothesis, we have $\mathrm{X}-\mathrm{U} \subseteq$ int $^{*}(\mathrm{~A})$ and hence $(\mathrm{X}-\mathrm{A})^{*} \subseteq \operatorname{cl}^{*}(\mathrm{X}-\mathrm{A})=\mathrm{X}-\mathrm{int}^{*}(\mathrm{~A}) \subseteq \mathrm{U}$. Therefore $\mathrm{X}-\mathrm{A}$ is $\alpha \operatorname{Ig}$ closed and $\mathrm{A}$ is $\alpha \mathrm{Ig}$ open.

\section{Theorem 3.32}

Let $(\mathrm{X}, \tau, \mathrm{I})$ be an ideal space and $\mathrm{A} \subseteq \mathrm{X}$. If $\mathrm{A}$ is $\alpha \mathrm{Ig}$ open and int $^{*}(\mathrm{~A}) \subseteq \mathrm{B} \subseteq \mathrm{A}$, then $\mathrm{B}$ is $\alpha \mathrm{Ig}$-open.

\section{Proof}

Since A is $\alpha$ Ig open, then $\mathrm{X}-\mathrm{A}$ is $\alpha \mathrm{Ig}$ closed. By Theorem 3.4(d), $\mathrm{cl}^{*}(\mathrm{X}-\mathrm{A})-(\mathrm{X}-\mathrm{A})$ contains no nonempty $\alpha$-closed set. Since int $^{*}(A) \subseteq$ int $^{*}(B), X-\operatorname{cl}^{*}(X-A) \subseteq X-\operatorname{cl}^{*}(X-B)$ which implies that $\operatorname{cl}^{*}(X-B) \subseteq$ $\operatorname{cl}^{*}(\mathrm{X}-\mathrm{A})$ and $\operatorname{socl}^{*}(\mathrm{X}-\mathrm{B})-(\mathrm{X}-\mathrm{B}) \subseteq \mathrm{cl}^{*}(\mathrm{X}-\mathrm{A})-(\mathrm{X}-\mathrm{A})$. Hence $\mathrm{B}$ is $\alpha \mathrm{Ig}$ open.

\section{Theorem 3.33}

Let $(X, \tau, I)$ be an ideal space. Then, every subset of $X$ is $\alpha$ Ig-closed if and only if every $\alpha$-open set is $*$-closed.

\section{Proof}

Suppose every subset of $\mathrm{X}$ is $\alpha \mathrm{Ig}$-closed. If $\mathrm{U} \subseteq \mathrm{X}$ is $\alpha$-open, then $\mathrm{U}$ is $\alpha \mathrm{Ig}$-closed and so $\mathrm{U}^{*} \subseteq \mathrm{U}$. Hence $\mathrm{U}$ is *-closed. Conversely, suppose that every $\alpha$-open set is *-closed. If $U$ is $\alpha$-open set such that $A \subseteq U \subseteq X$, then $\mathrm{A}^{*} \subseteq \mathrm{U} \subseteq \mathrm{X}$ and so $\mathrm{A}$ is $\alpha$ Ig-closed.

\section{Theorem 3.34}


If $\mathrm{A}$ and $\mathrm{B}$ are $\alpha$ Ig-open sets in $(\mathrm{X}, \tau, \mathrm{I})$, then $\mathrm{A} \cap \mathrm{B}$ is an $\alpha$ Ig-open set.

Proof

If $\mathrm{A}$ and $\mathrm{B}$ are $\alpha \mathrm{Ig}$-open sets, then $\mathrm{X}-\mathrm{A}$ and $\mathrm{X}-\mathrm{B}$ are $\alpha$ Ig-closed sets. By Theorem 3.22,

$(\mathrm{X}-\mathrm{A}) \cup(\mathrm{X}-\mathrm{B})$ is an $\alpha \mathrm{Ig}$-closed set, which implies that $\mathrm{X}-(\mathrm{A} \cap \mathrm{B})$ is an $\alpha \mathrm{Ig}$-closed set. Hence $\mathrm{A} \cap \mathrm{B}$ is an $\alpha \operatorname{Ig}-$ open set.

\section{References}

[1]. O.Njastad, On some classes of nearly open sets, Pacific J.Math.,15(1965),961-970

[2]. A.S. Mashhour, I.N.Hasanein and S.N. El-Deeb, $\alpha$-continuous and $\alpha$-open mappings, Acta Math.Hungar.,41(1983),213-218.

[3]. R.Vaidynathaswamy, The localization theory in set topology, Proc. Indian Acad. Sci. Math.Sci., 20(1945), 51-61.

[4]. R.L.Newcomb, Topologies which are compact modulo an ideal Ph.D, Dissertation. Univ.Ca;.at Santa Barbara,1967.

[5]. D.V. Rancin, Compactness modulo an ideal, Societ Math.Dokl.,13,193-197.1972

[6]. T.R. Hamlett and D. Jankovic, Compactness with respect to an ideal, Boll. Un. Mat. Ita.,(7), 4-B, 849-861,1990.

[7]. T.R. Hamlett and D. Jankovic, Ideals in topological spaces and the set operator, Boll. Un. Mat. Ita., 7, 863-874, 1990.

[8]. T.R. Hamlett and D. Jankovic, Ideals in General Topology and Applications (Midletown,CT,1998),115-125, Lecture Notes in Pure and Appl.Math. Dekker, New York, 1990.

[9]. D.Jankovic and T.R. Hamlett, ,New topology from old via ideals, Amer. Math. Month., 97. 295-310. 1990.

[10]. T.R. Hamlett and D. Jankovic , Compacible extensions of ideals ,Boll. Un. Mat. Ita., 7,453-465,1992.

[11]. J.Antony Rex Rodrigo, O.Ravi, A.Nalini ramalatha, $\hat{g}$-Closed sets in ideal topological spaces, Method of functional analysis and topology,Vol. 17(2011), no. 3,pp-274-280.

[12]. O.Ravi,S.Tharmar,J.Antony Rex Rodrigo and M. Sangeetha ,Between *-closed sets and $\mathrm{I}_{\mathrm{g}}$-closed sets in ideal topological spaces, International Journal of Advances In Pure and Applied Mathematics ,vol 1(2011),38-51.

[13]. A.Pushpalatha, S.Eswaran and P.Rajarubi, $\tau^{*}$-Generalized closed sets in Topological Spaces, Proceedings of the world congress on Engineering 2009, Vol II,WCF 2009,July 1-3, 2009, London, U.K.

[14]. Erdal Ekict, On Pre-I-Open sets, Semi-I-Open sets and b-I-Open sets in Ideal topological spaces,Acta Universitatis Apulensis ISSN: $1582-5329$, No. 30/2012, pp. 293-303.

[15]. P. Sundaram , N. Rajesh, M. Lellis Thivagar , Zbigniew Duszynski , On g^-closed sets in topological spaces, Mathematica Pannonica, 18/1 (2007), 51-61 